Lizandra da Silva Menegon

(iD) https://orcid.org/0000-0003-1326-5211

Fabrício Augusto Menegon ${ }^{\mathrm{a}}$

iD https://orcid.org/0000-0003-4516-6162

Emil Kupek ${ }^{\mathrm{a}}$

(iD) https://orcid.org/0000-0001-6704-1673

a Universidade Federal de Santa Catarina (UFSC), Departamento de Saúde Pública, Programa de Pós-Graduação em Saúde Coletiva. Florianópolis, SC, Brasil.

Contato:

Lizandra da Silva Menegon

E-mail:

lizandra.menegon@ufsc.br

Os autores declaram que o estudo não foi subvencionado e que não há conflitos de interesses.

Os autores informam que o trabalho não foi apresentado em evento científico.

\section{Mortalidade por acidentes de trabalho no Brasil: análise de tendência temporal, 2006-2015}

\author{
Mortality from occupational accidents in Brazil: \\ temporal trend analysis, 2006-2015
}

\section{Resumo}

Objetivo: analisar a tendência temporal da mortalidade por acidentes de trabalho (AT) no Brasil de 2006 a 2015 e investigar desigualdades segundo sexo, raça/cor da pele, faixa etária, escolaridade e macrorregiões. Métodos: estudo ecológico de tendência temporal, com dados do Sistema de Informações sobre Mortalidade (SIM) e do Instituto Brasileiro de Geografia e Estatística (IBGE). Utilizaram-se regressões de Poisson. Resultados: as taxas anuais médias (TAM) de mortalidade por acidente de trabalho mantiveram-se relativamente estáveis no período (variação anual de até 5\%), mas alguns grupos e regiões apresentaram tendência de aumento. Mulheres acima de 60 anos da região Centro-Oeste (TAM: 1,21-IC95\%: 1,03-1,42) e os trabalhadores pardos de todas as regiões (TAM: 1,03 IC95\%: 1,021,04) apresentaram aumento significativo na mortalidade. Em 2015, a mortalidade por AT na região Nordeste foi $88 \%$ maior entre os pardos (2,45/100 mil) do que entre os brancos (1,30/100 mil), e no Brasil, a mortalidade de trabalhadores com menos de oito anos de estudo foi 15 vezes superior à daqueles com 12 anos de estudo ou mais (4,74/100 mil vs. 0,31/100 mil). Conclusões: embora estável, a taxa de mortalidade por AT no Brasil é elevada, se comparada à dos países de alta renda. Alguns grupos populacionais (homens, pretos, pardos, índios, pessoas com baixa escolaridade) e regiões do país (Norte, Nordeste e Centro-Oeste) apresentam taxas ainda mais elevadas.

Palavras-chave: acidentes de trabalho; mortalidade ocupacional; saúde do trabalhador; desigualdades em saúde; estudos de séries temporais.

\begin{abstract}
Objective: to analyze the temporal trend of mortality due to occupational accidents $(O A)$ in Brazil from 2006 to 2015 and investigate inequalities related to gender, race/skin color, age group, education level, and macro-regions. Methods: ecological time series study conducted with data from the Mortality Information System (SIM) and the Brazilian Institute of Geography and Statistics (IBGE). Data were analyzed by Poisson regressions. Result: the average annual rate (AAR) for deaths due to $O A$ remained relatively stable over the analyzed period (annual variation of up to 5\%), but some groups and regions showed an upward trend. Mortality was significantly higher among women over 60 years old from the Midwest region (AAR: 1.21-95\%CI: 1.03-1.42) and brown-skinned people from all regions (AAR: 1.03-95\%CI: 1.021.04). In 2015, mortality from $O A$ in the Northeast region was $88 \%$ higher among brown-skinned people $(2.45 / 100,000)$ than among white people $(1.30 / 100,000)$. In Brazil, mortality was 15 times higher among individuals with less than eight school years when compared to those with 12 school years or more (4.74/100,000 vs. 0.31/100,000). Conclusions: although stable, the mortality rate due to $O A$ in Brazil is elevated when compared to high-income countries. These rates are even higher among some population groups (men, Blacks, brown-skinned, indigenous, and lower-educated people) and in certain regions of the country (North, Northeast, and Midwest).
\end{abstract}

Keywords: occupational accident; occupational mortality, occupational health; health inequalities; time-series studies. 


\section{Introdução}

Os acidentes de trabalho causam prejuízos graves à saúde pública, tais como afastamentos do trabalho, perda da capacidade para o trabalho, manifestações de dor, sofrimento emocional, problemas familiares, transtornos mentais e comportamentais, além dos óbitos. Tais ocorrências geram um custo considerável, pois além de empobrecerem os trabalhadores e suas famílias, reduzem a produtividade, a capacidade para o trabalho, e aumentam drasticamente os gastos com saúde. Nessa perspectiva, a Organização Internacional do Trabalho (OIT) estima uma perda anual de $4 \%$ do produto interno bruto (PIB) no mundo decorrente de acidentes de trabalho e doenças profissionais ${ }^{1}$.

A OIT estima que a cada ano ocorram 160 milhões de acidentes de trabalho no mundo e 2,34 milhões de pessoas morram por acidentes ou doenças relacionadas ao trabalho ${ }^{1}$. O maior componente da mortalidade corresponde às doenças relacionadas ao trabalho (2 milhões), enquanto 0,3 milhões são relacionadas a lesões ocupacionais. A distribuição das causas de óbitos nesses dois grupos está relacionada ao nível de renda dos países. Nos de renda alta, a quantidade de mortes devido a lesões ocupacionais e doenças transmissíveis relacionadas ao trabalho é muito baixa, sendo as doenças não transmissíveis a principal causa de óbitos nesses países² ${ }^{2}$.

O Brasil ocupa o quarto lugar no ranking mundial de acidentes de trabalho fatais, ficando atrás apenas da China, Estados Unidos e Rússia ${ }^{1}$. De acordo com dados do Anuário Estatístico da Previdência Social, em 2017, ocorreram 572.169 acidentes de trabalho liquidados no Brasil, dos quais 12.651 acarretaram incapacidade permanente aos trabalhadores e 2.096 foram causadores de óbito ${ }^{3}$.

No período de 1998 a 2008, foram registrados, no Brasil, 3.475.504 acidentes de trabalho, incluídos os típicos e os de trajeto, ocorridos com trabalhadores com 25 anos de idade ou mais, segurados pelo Instituto Nacional do Seguro Social (INSS) ${ }^{4}$. Nesse período, o número de óbitos e a taxa de mortalidade registraram tendência de decréscimo. Na taxa de mortalidade, o decréscimo considerando ambos os sexos foi significativo, passando de 21,2 para 9,9 óbitos a cada 100 mil trabalhadores. Entretanto, o número de casos e a incidência de acidentes de trajeto mostraram tendência significativa de aumento. Cumpre destacar que tal estudo foi realizado com uma base de dados constituída exclusivamente por trabalhadores segurados pela Previdência Social, ou seja, exclui todos os trabalhadores informais ou não-celetistas ${ }^{4}$. Dessa forma, supõe-se que os dados advindos da previdência social brasileira não reflitam toda a realidade do país.
Dados da Pesquisa Nacional de Saúde de 2013 apontaram que 4,9 milhões de trabalhadores brasileiros mencionaram ter sofrido algum tipo de acidente de trabalho, o que representa 3,4\% (IC95\% $4,6 ; 5,6)$ da população adulta. As maiores frequências foram observadas em homens, entre $18 \mathrm{e}$ 39 anos, negros (pretos mais pardos) e residentes na região Norte do país ${ }^{5}$.

A maioria dos países não possui fontes confiáveis e padronizadas para obtenção de informações sobre acidentes de trabalho e doenças ocupacionais, logo, não se sabe ao certo o número de mortes em todo o mundo ${ }^{6}$. Os países de baixa e média renda, especialmente, apresentam maiores frequências de subnotificação, além de informações menos confiáveis sobre seus acidentes devido à falta de sistemas adequados de registro e notificação. Apesar disso, esses números ainda são usados para subsidiar as ações de segurança e saúde do trabalhador ${ }^{7}$.

Embora vários estudos evidenciem uma importante subnotificação dos acidentes de trabalho no Brasil $^{5,8-12}$, as taxas de mortalidade ainda são altas quando comparadas às de países de alta renda. Por exemplo, no ano de 2008, a taxa de mortalidade no Brasil era de 9,9/100 mil trabalhadores ${ }^{4}$, enquanto na Alemanha era de 2/100 mil e na Suíça, de $1,1 / 100 \mathrm{mil}^{13}$.

A precariedade de informações públicas e de dados oficiais sobre acidentes de trabalho no Brasil dificulta a análise e a interpretação dos fatores que influenciam ou que potencializam o risco de o trabalhador sofrer um agravo, constituindo um grave problema de saúde pública. A escassez e inconsistência das informações sobre a real situação de saúde dos trabalhadores comprometem a definição das prioridades para as políticas públicas, o planejamento e a implementação das ações de Saúde do Trabalhador ${ }^{10}$.

Estudos internacionais trazem inúmeras evidências da influência dos aspectos étnicos e raciais na incidência e no risco de acidentes de trabalho ${ }^{14-16}$. Melchior e Zaninni ${ }^{17}$ analisaram 102 estudos sobre acidentes ocupacionais fatais publicados entre 2001 e 2018, indicando que a maioria analisou idade, sexo e grupos étnicos dos trabalhadores. Entretanto, atualmente no Brasil há poucos estudos de tendência de mortalidade por acidente de trabalho, especialmente no que se refere às características étnico-raciais, de sexo, escolaridade e diferenças regionais.

Nesse sentido, este estudo objetiva analisar a tendência temporal da mortalidade por acidentes de trabalho no Brasil de 2006 a 2015 e investigar desigualdades segundo sexo, raça/cor da pele, faixa etária, escolaridade e macrorregiões. 


\section{Métodos}

Foi realizado um estudo ecológico de tendência temporal. Os dados sobre os óbitos foram obtidos a partir da base de dados do Sistema de Informações sobre Mortalidade (SIM), disponível no portal eletrônico do Departamento de Informática do Sistema Único de Saúde (DATASUS) ${ }^{18}$.

Foram incluídos os óbitos por causas externas, por acidentes de trabalho, de pessoas acima de 15 anos, residentes no Brasil, ocorridos entre 2006 e 2015, por local de ocorrência.

Obteve-se os números de óbitos por acidente de trabalho segundo as variáveis: ano do óbito (2006 a 2015), sexo (masculino e feminino), cor da pele (branca, preta, parda, amarela, indígena), faixa etária (15-19, 20-29, 30-39, 40-49, 50-59 e 60 anos ou mais), escolaridade (médio completo e superior [12 anos de estudo ou mais], fundamental completo e médio incompleto [8 a 11 anos de estudo], sem instrução e fundamental incompleto [0 a 7 anos de estudo]) e macrorregiões do Brasil (Norte, Nordeste, Sudeste, Sul e Centro-Oeste).

O tamanho da população economicamente ativa ocupada, conforme categorias das variáveis de interesse, foi obtido de tabulações da Pesquisa Nacional por Amostra de Domicílios (PNAD) dos anos de 2006 a 2015, exceto 2010, que foi obtido a partir do Censo Demográfico. Todas as informações sobre população foram obtidas no site do Instituto Brasileiro de Geografia e Estatística (IBGE) e as tabelas foram geradas por meio do Sistema IBGE de Recuperação Automática (Sidra) ${ }^{\mathrm{b}}$.

Para a organização e o processamento dos dados, foram criadas planilhas no Microsoft Excel 2007 que posteriormente foram exportadas para o programa estatístico Stata SE 13.1 (Stata Corp., College Station, 2013) para análise estatística.

Os dados da categoria ignorados na base de dados do SIM foram apresentados devido a sua importância para a qualidade das informações. Esses dados representam os campos que não foram preenchidos na declaração de óbitos (DO), documento básico do SIM. Para as análises de regressão, essas informações foram excluídas.

Foram construídos modelos de regressão de Poisson para estimar o Risco Relativo de mortalidade de acordo com categorias de faixa etária, macrorregiões do país, raça/cor da pele, escolaridade e sexo nas tendências das taxas de mortalidade por acidente de trabalho no período estudado. Foi utilizado o critério de valor $\mathrm{p}<0,20$ para erro tipo I com relação à entrada no modelo multivariável, e o valor $\mathrm{p}<0,05$ para manutenção da variável no modelo. A variação das taxas de mortalidade foi avaliada com intervalos de confiança de 95\% (IC95\%). O ajuste do modelo também foi verificado por meio da análise de resíduos (distribuição e magnitude).

A regressão de Poisson também foi utilizada para avaliar a tendência temporal da taxa de mortalidade, operacionalizada como a taxa anual média no período (TAM), e sua significância estatística com base nos intervalos de confiança.

A variação da mortalidade segundo as características populacionais raça/cor, escolaridade e faixa etária passou por três análises de Poisson separadas.

Como trata-se de um estudo que utilizou dados disponíveis publicamente em fontes oficiais (Ministério da Saúde e IBGE), que não permitem a identificação dos sujeitos e são analisados de maneira agregada, o projeto não foi submetido a comitê de ética em pesquisa.

\section{Resultados}

No período entre 2006 e 2015 ocorreram 33.480 óbitos por acidentes de trabalho no Brasil entre pessoas com mais de 15 anos de idade. desses, houve 54 casos em que a faixa etária foi ignorada no momento do preenchimento da DO. Em relação às faixas etárias, 1.349 (4\%) tinham entre 15 e 19 anos, 7.739 (23\%) entre 20 e 29 anos, 8.217 (25\%) entre 30 e 39 anos, 7.489 (22\%) entre 40 e 49 anos, 5.440 (16\%) entre 50 e 59 anos, e 3190 (10\%) dos trabalhadores tinham 60 anos de idade ou mais.

Com relação ao sexo, 31.786 (95\%) dos óbitos no período ocorreram entre homens, 1.684 (5\%) entre mulheres e houve dez casos em que este campo foi ignorado. De acordo com a raça/cor, 17.290 (52\%) dos óbitos ocorreram com trabalhadores brancos, 1.962 (6\%) com pretos, 13.198 (39\%) pardos, 95 (0\%) amarelos, $60(0 \%)$ indígenas e houve 875 (3\%) casos ignorados. Em relação à escolaridade, 14.858 (44\%) dos trabalhadores que foram a óbito careciam de instrução formal ou tinham fundamental incompleto (0 a 7 anos

b As tabelas estão disponíveis em: (i) Censo Demográfico 2010: https://sidra.ibge.gov.br/tabela/3581\#/n1/all/n2/all/v/allxp/p/ all/c1/0/c2/all/c86/all/c1568/all/c521/0/c58/0,1143,1144,1145,1146,1147,1148,1149,1150,1151,3244,3520/d/v916\%200/ $\mathrm{l} / \mathrm{v}, \mathrm{p}+\mathrm{c} 1+\mathrm{c} 2+\mathrm{c} 86, \mathrm{t}+\mathrm{c} 1568+\mathrm{c} 521+\mathrm{c} 58 /$ resultado;

(ii) PNAD 2006-2015 de acordo com região, raça e sexo: https://sidra.ibge.gov.br/tabela/4040\#/n1/all/n2/all/v/allxp/p/all/c1/0/c2/ allxt/c86/all/d/v1139\%200/l/v,p+c1+c2,t+c86/resultado;

(iii) PNAD 2006-2015 de acordo com região, escolaridade e sexo: https:/sidra.ibge.gov.br/tabela/4036\#/n1/all/n2/all/v/allxp/p/ all/c12031/0/c2/all/c71/all/d/v1139\%200/l/v,p+c12031+c2,t+c71/resultado 
de estudo), 7.648 (23\%) tinham ensino fundamental completo ou médio incompleto (8 a 11 anos de estudo) e 1.709 (5\%) tinham ensino médio completo ou superior (12 anos de estudo ou mais). Para esta variável, observou-se um total de 9.265 (28\%) casos ignorados.

Conforme a distribuição geográfica dentre as macrorregiões do Brasil, 3.582 (10\%) dos óbitos ocorreram no Norte, 5.372 (16\%) no Nordeste, 11.601 (35\%) no Sudeste, 8.332 (26\%) no Sul e 4.595 (13\%) na região Centro-Oeste. Para a variável região não houve nenhum caso ignorado.
A análise das taxas de mortalidade por acidente de trabalho revelou diferenças segundo sexo e faixa etária. Para o sexo masculino, taxas de mortalidade acima de 13/100 mil trabalhadores foram observadas nas regiões Sul e Centro-Oeste. A taxa de mortalidade mais baixa para os homens é de 1,77/100 mil trabalhadores na região Nordeste, entre pessoas com 15 a 19 anos de idade (no ano de 2006), enquanto a taxa mais alta observada é de 13,25/100 mil trabalhadores na região Centro-Oeste, entre trabalhadores com 60 anos de idade ou mais (Tabela 1).

Tabela 1 Número de óbitos e taxa de mortalidade por acidentes de trabalho estimada por 100 mil trabalhadores por ano e por período, de acordo com sexo, faixa etária e macrorregião do Brasil, 2006 a 2015

\begin{tabular}{|c|c|c|c|c|c|c|c|c|c|c|c|c|c|}
\hline \multirow{3}{*}{ Sexo e faixa etária } & \multicolumn{12}{|c|}{ Taxa de mortalidade } & \multirow[b]{2}{*}{ IC95\% } \\
\hline & (n) & 2006 & 2007 & 2008 & 2009 & 2010 & 2011 & 2012 & 2013 & 2014 & 2015 & TAM & \\
\hline & \multicolumn{13}{|c|}{ Sexo masculino } \\
\hline \multicolumn{14}{|l|}{ Sudeste } \\
\hline 15 a 19 anos & 342 & 2,23 & 2,35 & 2,35 & 2,42 & 2,83 & 2,71 & 2,73 & 2,79 & 2,55 & 2,34 & $1,05^{*}$ & $1,02-1,09$ \\
\hline 20 a 29 anos & 2.369 & 3,81 & 4,01 & 4,01 & 4,13 & 4,83 & 4,62 & 4,65 & 4,75 & 4,35 & 4,00 & 0,99 & $0,98-1,00$ \\
\hline 30 a 39 anos & 2.720 & 4,25 & 4,47 & 4,47 & 4,60 & 5,39 & 5,15 & 5,19 & 5,30 & 4,86 & 4,46 & 1,00 & $0,99-1,02$ \\
\hline 40 a 49 anos & 2.593 & 4,61 & 4,86 & 4,86 & 5,00 & 5,85 & 5,60 & 5,64 & 5,76 & 5,27 & 4,85 & 0,99 & $0,98-1,00$ \\
\hline 50 a 59 anos & 2.013 & 5,12 & 5,40 & 5,39 & 5,56 & 6,50 & 6,22 & 6,26 & 6,40 & 5,86 & 5,38 & 0,99 & $0,98-1,01$ \\
\hline 60 anos ou mais & 1.035 & 5,23 & 5,51 & 5,51 & 5,67 & 6,64 & 6,35 & 6,39 & 6,53 & 5,98 & 5,50 & $1,03^{*}$ & $1,01-1,05$ \\
\hline \multicolumn{14}{|l|}{ Sul } \\
\hline 15 a 19 anos & 377 & 5,46 & 5,75 & 5,75 & 5,92 & 6,93 & 6,63 & 6,67 & 6,82 & 6,24 & 5,74 & $1,04^{*}$ & $1,00-1,08$ \\
\hline 20 a 29 anos & 1.799 & 8,27 & 8,71 & 8,71 & 8,97 & 10,50 & 10,04 & 10,11 & 10,33 & 9,46 & 8,69 & $1,03^{*}$ & $1,01-1,04$ \\
\hline 30 a 39 anos & 1.805 & 8,36 & 8,80 & 8,80 & 9,06 & 10,60 & 10,14 & 10,22 & 10,44 & 9,56 & 8,78 & 1,00 & $0,98-1,02$ \\
\hline 40 a 49 anos & 1.834 & 9,05 & 9,53 & 9,52 & 9,81 & 11,48 & 10,98 & 11,06 & 11,30 & 10,34 & 9,51 & 1,00 & $0,99-1,02$ \\
\hline 50 a 59 anos & 1.449 & 9,92 & 10,44 & 10,44 & 10,75 & 12,58 & 12,03 & 12,12 & 12,38 & 11,33 & 10,42 & 1,00 & $0,98-1,02$ \\
\hline 60 anos ou mais & 854 & 10,28 & 10,83 & 10,82 & 11,15 & 13,04 & 12,48 & 12,57 & 12,84 & 11,75 & 10,80 & $1,05^{*}$ & $1,03-1,08$ \\
\hline \multicolumn{14}{|l|}{ Norte } \\
\hline 15 a 19 anos & 154 & 3,75 & 3,95 & 3,95 & 4,07 & 4,76 & 4,56 & 4,59 & 4,69 & 4,29 & 3,94 & 1,05 & $0,99-1,10$ \\
\hline 20 a 29 anos & 867 & 6,62 & 6,97 & 6,97 & 7,18 & 8,40 & 8,03 & 8,09 & 8,27 & 7,57 & 6,95 & 1,00 & $0,97-1,02$ \\
\hline 30 a 39 anos & 917 & 7,35 & 7,74 & 7,74 & 7,97 & 9,32 & 8,92 & 8,98 & 9,18 & 8,40 & 7,72 & 1,02 & $1,00-1,05$ \\
\hline 40 a 49 anos & 745 & 7,90 & 8,32 & 8,32 & 8,57 & 10,03 & 9,59 & 9,66 & 9,87 & 9,04 & 8,30 & 1,00 & $0,98-1,03$ \\
\hline 50 a 59 anos & 416 & 6,77 & 7,13 & 7,12 & 7,34 & 8,58 & 8,21 & 8,27 & 8,45 & 7,74 & 7,11 & $1,05^{*}$ & $1,01-1,08$ \\
\hline 60 anos ou mais & 250 & 7,42 & 7,82 & 7,81 & 8,05 & 9,42 & 9,01 & 9,07 & 9,27 & 8,49 & 7,80 & 1,01 & $0,97-1,06$ \\
\hline \multicolumn{14}{|l|}{ Nordeste } \\
\hline 15 a 19 anos & 224 & 1,77 & 1,86 & 1,86 & 1,91 & 2,24 & 2,14 & 2,16 & 2,21 & 2,02 & 1,86 & 1,04 & $1,00-1,09$ \\
\hline 20 a 29 anos & 1.286 & 3,19 & 3,36 & 3,36 & 3,46 & 4,05 & 3,87 & 3,90 & 3,98 & 3,65 & 3,35 & 1,03 & $1,00-1,05$ \\
\hline 30 a 39 anos & 1.363 & 3,56 & 3,75 & 3,75 & 3,86 & 4,52 & 4,33 & 4,36 & 4,45 & 4,08 & 3,75 & $1,03^{*}$ & $1,01-1,05$ \\
\hline 40 a 49 anos & 1.033 & 3,33 & 3,50 & 3,50 & 3,61 & 4,22 & 4,04 & 4,07 & 4,15 & 3,80 & 3,50 & 1,02 & $1,00-1,04$ \\
\hline 50 a 59 anos & 689 & 3,32 & 3,49 & 3,49 & 3,59 & 4,21 & 4,02 & 4,05 & 4,14 & 3,79 & 3,48 & 1,04 & $1,00-1,06$ \\
\hline 60 anos ou mais & 449 & 3,31 & 3,48 & 3,48 & 3,59 & 4,20 & 4,01 & 4,04 & 4,13 & 3,78 & 3,48 & $1,05^{*}$ & $1,01-1,08$ \\
\hline \multicolumn{14}{|l|}{ Centro-Oeste } \\
\hline 15 a 19 anos & 160 & 4,74 & 5,00 & 4,99 & 5,14 & 6,02 & 5,76 & 5,80 & 5,92 & 5,42 & 4,98 & $1,10^{* *}$ & $1,04-1,16$ \\
\hline 20 a 29 anos & 994 & 8,38 & 8,82 & 8,82 & 9,08 & 10,63 & 10,16 & 10,24 & 10,46 & 9,57 & 8,80 & 1,00 & $0,98-1,03$ \\
\hline 30 a 39 anos & 1.016 & 8,51 & 8,96 & 8,96 & 9,23 & 10,80 & 10,33 & 10,40 & 10,63 & 9,73 & 8,94 & 0,99 & $0,97-1,02$ \\
\hline 40 a 49 anos & 964 & 9,77 & 10,28 & 10,28 & 10,59 & 12,39 & 11,85 & 11,94 & 12,20 & 11,16 & 10,26 & 1,00 & $0,98-1,02$ \\
\hline 50 a 59 anos & 665 & 10,37 & 10,92 & 10,92 & 11,24 & 13,16 & 12,59 & 12,68 & 12,95 & 11,86 & 10,90 & 1,03 & $1,00-1,06$ \\
\hline 60 anos ou mais & 360 & 10,45 & 11,00 & 10,99 & 11,32 & 13,25 & 12,67 & 12,77 & 13,04 & 11,94 & 10,97 & 1,00 & $0,97-1,04$ \\
\hline
\end{tabular}

(continua) 
Tabela 1 Continuação

\begin{tabular}{|c|c|c|c|c|c|c|c|c|c|c|c|c|c|}
\hline \multirow[b]{2}{*}{ Sexo e faixa etária } & \multicolumn{12}{|c|}{ Taxa de mortalidade } & \multirow[b]{2}{*}{ IC95\% } \\
\hline & (n) & 2006 & 2007 & 2008 & 2009 & 2010 & 2011 & 2012 & 2013 & 2014 & 2015 & TAM & \\
\hline \multicolumn{14}{|l|}{ Brasil } \\
\hline 15 a 19 anos & 1.257 & 2,95 & 3,12 & 3,11 & 3,20 & 3,79 & 3,60 & 3,62 & 3,71 & 3,39 & 3,13 & $1,05^{*}$ & $1,03-1,07$ \\
\hline 20 a 29 anos & 7.315 & 4,88 & 5,15 & 5,13 & 5,29 & 6,26 & 5,95 & 5,99 & 6,12 & 5,61 & 5,17 & 1,01 & $1,00-1,01$ \\
\hline 30 a 39 anos & 7.821 & 5,25 & 5,54 & 5,53 & 5,70 & 6,74 & 6,40 & 6,44 & 6,59 & 6,04 & 5,57 & 1,01 & $1,00-1,02$ \\
\hline 40 a 49 anos & 7.169 & 5,63 & 5,94 & 5,92 & 6,11 & 7,22 & 6,86 & 6,91 & 7,06 & 6,47 & 5,97 & 1,00 & $0,99-1,01$ \\
\hline 50 a 59 anos & 5.232 & 5,97 & 6,30 & 6,28 & 6,48 & 7,66 & 7,28 & 7,33 & 7,50 & 6,86 & 6,33 & 1,01 & $1,00-1,02$ \\
\hline 60 anos ou mais & 2.948 & 6,05 & 6,39 & 6,37 & 6,57 & 7,77 & 7,38 & 7,43 & 7,60 & 6,96 & 6,42 & $1,03^{*}$ & $1,02-1,05$ \\
\hline \multicolumn{14}{|c|}{ Sexo feminino } \\
\hline \multicolumn{14}{|l|}{ Sudeste } \\
\hline 15 a 19 anos & 25 & 0,24 & 0,25 & 0,25 & 0,26 & 0,30 & 0,29 & 0,29 & 0,30 & 0,27 & 0,25 & 1,09 & $0,95-1,25$ \\
\hline 20 a 29 anos & 138 & 0,29 & 0,30 & 0,30 & 0,31 & 0,36 & 0,35 & 0,35 & 0,36 & 0,33 & 0,30 & $1,10^{\text {粰 }}$ & $1,03-1,17$ \\
\hline 30 a 39 anos & 138 & 0,26 & 0,28 & 0,28 & 0,29 & 0,33 & 0,32 & 0,32 & 0,33 & 0,30 & 0,28 & 1,05 & $0,99-1,11$ \\
\hline 40 a 49 anos & 110 & 0,24 & 0,25 & 0,25 & 0,26 & 0,30 & 0,29 & 0,29 & 0,30 & 0,27 & 0,25 & 0,98 & $0,93-1,05$ \\
\hline 50 a 59 anos & 70 & 0,24 & 0,25 & 0,25 & 0,26 & 0,30 & 0,29 & 0,29 & 0,30 & 0,27 & 0,25 & 1,02 & $0,94-1,10$ \\
\hline 60 anos ou mais & 83 & 0,74 & 0,78 & 0,78 & 0,80 & 0,93 & 0,89 & 0,90 & 0,92 & 0,84 & 0,77 & 0,99 & $0,93-1,07$ \\
\hline \multicolumn{14}{|l|}{ Sul } \\
\hline 15 a 19 anos & 34 & 0,72 & 0,75 & 0,75 & 0,78 & 0,91 & 0,87 & 0,87 & 0,89 & 0,82 & 0,75 & 1,03 & $0,92-1,16$ \\
\hline 20 a 29 anos & 142 & 0,81 & 0,85 & 0,85 & 0,88 & 1,03 & 0,98 & 0,99 & 1,01 & 0,93 & 0,85 & 1,03 & $0,98-1,10$ \\
\hline 30 a 39 anos & 127 & 0,70 & 0,74 & 0,73 & 0,76 & 0,89 & 0,85 & 0,85 & 0,87 & 0,80 & 0,73 & 1,01 & $0,95-1,07$ \\
\hline 40 a 49 anos & 111 & 0,65 & 0,68 & 0,68 & 0,70 & 0,82 & 0,78 & 0,79 & 0,81 & 0,74 & 0,68 & 1,00 & $0,94-1,07$ \\
\hline 50 a 59 anos & 64 & 0,57 & 0,60 & 0,60 & 0,62 & 0,73 & 0,69 & 0,70 & 0,71 & 0,65 & 0,60 & 1,02 & $0,94-1,11$ \\
\hline 60 anos ou mais & 64 & 1,27 & 1,33 & 1,33 & 1,37 & 1,61 & 1,54 & 1,55 & 1,58 & 1,45 & 1,33 & 1,08 & $0,99-1,18$ \\
\hline \multicolumn{14}{|l|}{ Norte } \\
\hline 15 a 19 anos & 8 & 0,40 & 0,42 & 0,42 & 0,43 & 0,50 & 0,48 & 0,49 & 0,50 & 0,45 & 0,42 & 0,95 & $0,74-1,22$ \\
\hline 20 a 29 anos & 32 & 0,39 & 0,41 & 0,41 & 0,43 & 0,50 & 0,48 & 0,48 & 0,49 & 0,45 & 0,41 & 0,98 & $0,87-1,11$ \\
\hline 30 a 39 anos & 31 & 0,35 & 0,36 & 0,36 & 0,38 & 0,44 & 0,42 & 0,42 & 0,43 & 0,40 & 0,36 & 1,08 & $0,95-1,22$ \\
\hline 40 a 49 anos & 31 & 0,47 & 0,49 & 0,49 & 0,51 & 0,60 & 0,57 & 0,57 & 0,59 & 0,54 & 0,49 & 1,09 & $0,96-1,23$ \\
\hline 50 a 59 anos & 17 & 0,44 & 0,46 & 0,46 & 0,47 & 0,55 & 0,53 & 0,53 & 0,55 & 0,50 & 0,46 & 1,01 & $0,86-1,19$ \\
\hline 60 anos ou mais & 21 & 1,59 & 1,67 & 1,67 & 1,72 & 2,02 & 1,93 & 1,94 & 1,99 & 1,82 & 1,67 & 0,95 & $0,83-1,08$ \\
\hline \multicolumn{14}{|l|}{ Nordeste } \\
\hline 15 a 19 anos & 16 & 0,24 & 0,25 & 0,25 & 0,26 & 0,31 & 0,29 & 0,30 & 0,30 & 0,28 & 0,25 & 0,98 & $0,83-1,16$ \\
\hline 20 a 29 anos & 72 & 0,26 & 0,28 & 0,28 & 0,29 & 0,33 & 0,32 & 0,32 & 0,33 & 0,30 & 0,28 & 1,01 & $0,93-1,09$ \\
\hline 30 a 39 anos & 70 & 0,24 & 0,25 & 0,25 & 0,26 & 0,30 & 0,29 & 0,29 & 0,30 & 0,27 & 0,25 & 1,00 & $0,92-1,09$ \\
\hline 40 a 49 anos & 44 & 0,18 & 0,19 & 0,19 & 0,20 & 0,23 & 0,22 & 0,22 & 0,23 & 0,21 & 0,19 & 1,01 & $0,91-1,12$ \\
\hline 50 a 59 anos & 36 & 0,24 & 0,25 & 0,25 & 0,26 & 0,30 & 0,29 & 0,29 & 0,30 & 0,27 & 0,25 & 0,96 & $0,85-1,07$ \\
\hline 60 anos ou mais & 51 & 0,69 & 0,72 & 0,72 & 0,75 & 0,87 & 0,83 & 0,84 & 0,86 & 0,79 & 0,72 & 1,00 & $0,92-1,10$ \\
\hline \multicolumn{14}{|l|}{ Centro-Oeste } \\
\hline 15 a 19 anos & 9 & 0,45 & 0,47 & 0,47 & 0,49 & 0,57 & 0,54 & 0,55 & 0,56 & 0,51 & 0,47 & 1,09 & $0,87-1,38$ \\
\hline 20 a 29 anos & 40 & 0,46 & 0,49 & 0,49 & 0,50 & 0,59 & 0,56 & 0,57 & 0,58 & 0,53 & 0,49 & 1,08 & $0,96-1,20$ \\
\hline 30 a 39 anos & 30 & 0,31 & 0,33 & 0,33 & 0,34 & 0,39 & 0,38 & 0,38 & 0,39 & 0,35 & 0,33 & 1,09 & $0,96-1,24$ \\
\hline 40 a 49 anos & 24 & 0,31 & 0,33 & 0,33 & 0,34 & 0,39 & 0,38 & 0,38 & 0,39 & 0,35 & 0,33 & 1,08 & $0,94-1,24$ \\
\hline 50 a 59 anos & 21 & 0,48 & 0,50 & 0,50 & 0,52 & 0,61 & 0,58 & 0,58 & 0,60 & 0,55 & 0,50 & 1,09 & $0,93-1,27$ \\
\hline 60 anos ou mais & 23 & 1,47 & 1,55 & 1,55 & 1,60 & 1,87 & 1,79 & 1,80 & 1,84 & 1,68 & 1,55 & $1,21^{\text {米米 }}$ & $1,03-1,42$ \\
\hline \multicolumn{14}{|l|}{ Brasil } \\
\hline 15 a 19 anos & 92 & 0,35 & 0,37 & 0,37 & 0,39 & 0,46 & 0,43 & 0,44 & 0,45 & 0,41 & 0,38 & 1,03 & $0,97-1,11$ \\
\hline 20 a 29 anos & 424 & 0,38 & 0,41 & 0,40 & 0,42 & 0,49 & 0,47 & 0,47 & 0,48 & 0,44 & 0,41 & $1,05^{*}$ & $1,02-1,09$ \\
\hline 30 a 39 anos & 396 & 0,33 & 0,35 & 0,35 & 0,36 & 0,43 & 0,41 & 0,41 & 0,42 & 0,38 & 0,35 & 1,03 & $1,00-1,07$ \\
\hline 40 a 49 anos & 320 & 0,31 & 0,33 & 0,33 & 0,34 & 0,40 & 0,38 & 0,38 & 0,39 & 0,36 & 0,33 & 1,01 & $0,97-1,05$ \\
\hline 50 a 59 anos & 208 & 0,32 & 0,34 & 0,34 & 0,35 & 0,42 & 0,40 & 0,40 & 0,41 & 0,37 & 0,34 & 1,01 & $0,97-1,06$ \\
\hline 60 anos ou mais & 242 & 0,91 & 0,96 & 0,96 & 0,99 & 1,17 & 1,11 & 1,12 & 1,14 & 1,05 & 0,97 & 1,03 & $0,99-1,08$ \\
\hline
\end{tabular}

* Leve tendência de crescimento nas taxas de mortalidade (até 5\%, em média, ao ano) com significância estatística; *** moderada tendência de crescimento nas taxas de mortalidade (entre 6 e 10\%, em média, ao ano) com significância estatística; ${ }^{*}$ *** forte tendência de crescimento nas taxas de mortalidade (acima de 11\%, em média, ao ano) com significância estatística; (n) refere-se ao número de óbitos por acidentes de trabalho no período; TAM refere-se à taxa anual média no período; IC95\% refere-se aos intervalos de confiança de 95\%.

Fonte: SIM/DATASUS/Ministério da Saúde ${ }^{18}$. 
A mortalidade por acidente de trabalho no Brasil se manteve estável em todas as faixas etárias, tanto para trabalhadores homens quanto para mulheres. Apesar disso, nota-se que as taxas são maiores entre o primeiro grupo. Com relação à faixa etária, a taxa de mortalidade mais alta ocorre entre aqueles com 60 anos de idade ou mais, independentemente do sexo (Figura 1).

A menor taxa de mortalidade entre os homens, a cada 100 mil trabalhadores, foi de 2,95 (entre 15 e 19 anos) em 2006, e a maior taxa de mortalidade foi de 7,77 (60 anos ou mais) em 2010. Os homens entre 15 e 19 anos foram os que tiveram maior tendência de crescimento na taxa de mortalidade, com aumento médio anual de $5 \%$.

Entre as mulheres, a taxa de mortalidade mais baixa foi de 0,18/100 mil trabalhadoras, na região Nordeste (40 a 49 anos). A taxa mais alta ocorreu na região Norte, chegando a 2,02/100 mil trabalhadoras com 60 anos ou mais. Aumento estatisticamente significativo foi observado para trabalhadoras de 20 a 29 anos no nível nacional, com grande contribuição da região Sudeste ( $5 \%$ ao ano). Destaca-se ainda forte tendência de crescimento, com significância estatística, nas taxas de mortalidade entre as trabalhadoras com 60 anos ou mais, da região Centro-Oeste, apresentando aumento médio de $21 \%$ ao ano.
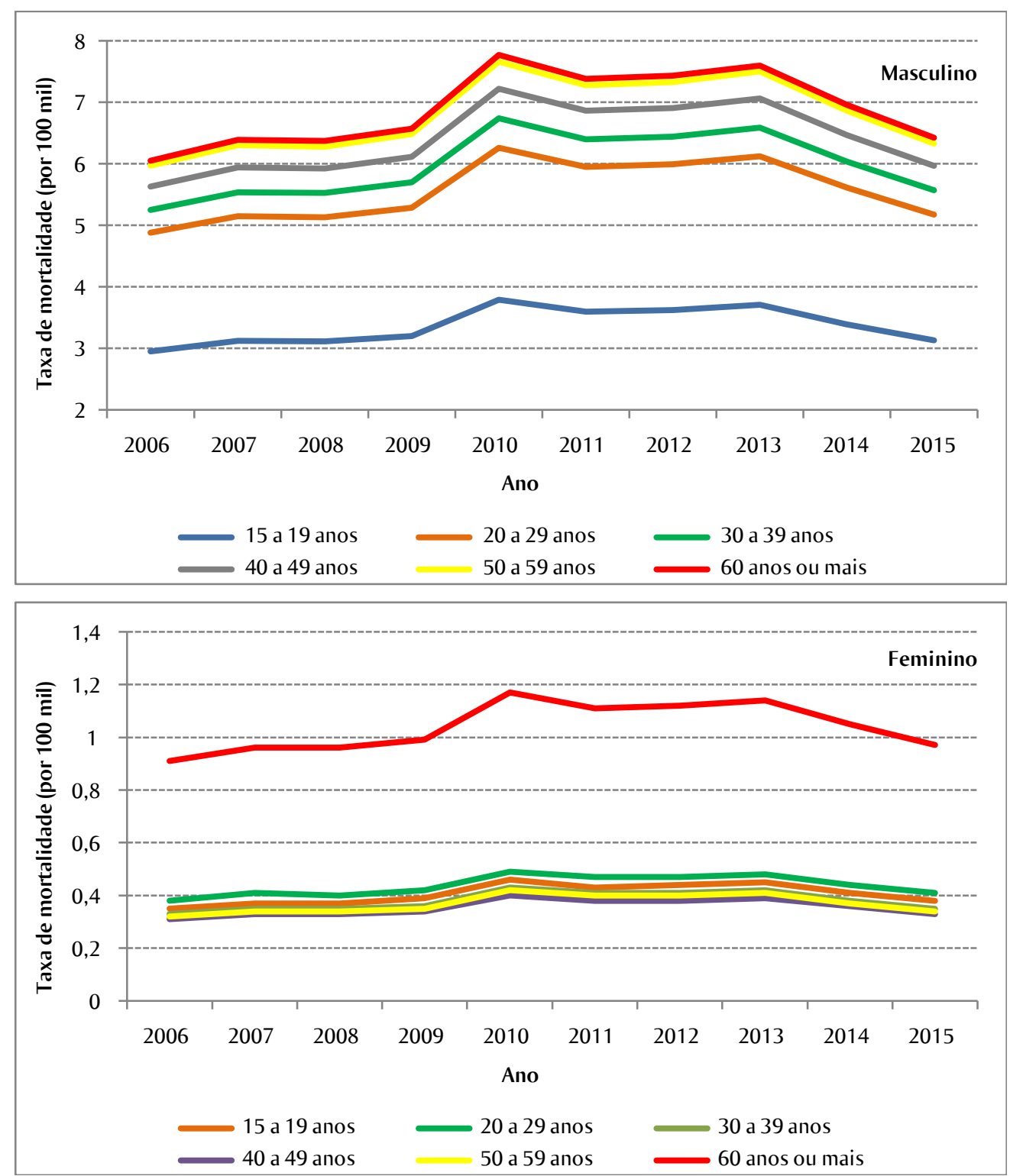

Figura 1 Taxa de mortalidade por acidente de trabalho (a cada 100 mil trabalhadores) de acordo com sexo e faixa etária, Brasil, 2006-2015 
Considerando o Brasil como um todo, observa-se que a taxa de mortalidade por acidente de trabalho entre as mulheres varia de 0,35/100 mil (15 a 19 anos) a 1,17/100 mil (60 anos de idade ou mais). A tendência de mortalidade entre as mulheres apresenta leve crescimento, com aumento médio anual de $5 \%$ dentre trabalhadoras com 20 e 29 anos de idade (Tabela 1).

Com relação à raça/cor de pele, é possível notar aumento leve, mas significativo, na mortalidade por acidente de trabalho entre os trabalhadores pardos de todas as regiões do país, com variação de 2 a $4 \%$; enquanto entre os trabalhadores brancos, só houve aumento significativo na região Sul (2\%). Embora os aumentos da taxa de mortalidade para amarelos de $68 \%$ no Nordeste e de $40 \%$ na indígena no CentroOeste também tenham sido estatisticamente significativos, ambas mostraram grande variação por causa do pequeno número óbitos $(<10)$ (Tabela 2).

Tabela 2 Número de óbitos e taxa de mortalidade estimada por acidentes de trabalho, por 100 mil trabalhadores, de acordo com ano, raça/cor e macrorregiões do Brasil, 2006 a 2015

\begin{tabular}{|c|c|c|c|c|c|c|c|c|c|c|c|c|c|}
\hline \multirow{2}{*}{$\frac{\text { Macrorregiões }}{\text { Raça/cor }}$} & \multirow[b]{2}{*}{ (n) } & \multicolumn{10}{|c|}{ Taxa de mortalidade para cada ano } & \multicolumn{2}{|c|}{$2006-2015$} \\
\hline & & 2006 & 2007 & 2008 & 2009 & 2010 & 2011 & 2012 & 2013 & 2014 & 2015 & TAM & IC (95\%) \\
\hline \multicolumn{14}{|l|}{ Sudeste } \\
\hline Branca & 6659 & 2,54 & 2,71 & 2,76 & 2,84 & 3,33 & 3,19 & 3,23 & 3,34 & 3,04 & 2,84 & 1,00 & $1,00-1,01$ \\
\hline Preta & 837 & 1,95 & 2,09 & 2,13 & 2,19 & 2,56 & 2,45 & 2,48 & 2,57 & 2,34 & 2,19 & 0,99 & $0,97-1,02$ \\
\hline Parda & 3738 & 2,28 & 2,44 & 2,49 & 2,56 & 3,00 & 2,87 & 2,91 & 3,00 & 2,73 & 2,56 & $1,02^{*}$ & $1,01-1,04$ \\
\hline Amarela & 51 & 1,31 & 1,41 & 1,43 & 1,47 & 1,73 & 1,65 & 1,67 & 1,73 & 1,57 & 1,47 & 0,97 & $0,88-1,07$ \\
\hline Indígena & 02 & 0,21 & 0,22 & 0,22 & 0,23 & 0,27 & 0,26 & 0,26 & 0,27 & 0,25 & 0,23 & 1,05 & $0,66-1,65$ \\
\hline \multicolumn{14}{|l|}{ Sul } \\
\hline Branca & 7547 & 5,50 & 5,89 & 5,99 & 6,17 & 7,23 & 6,92 & 7,00 & 7,24 & 6,59 & 6,16 & $1,02^{*}$ & $1,01-1,03$ \\
\hline Preta & 252 & 3,53 & 3,78 & 3,85 & 3,96 & 4,64 & 4,44 & 4,50 & 4,65 & 4,23 & 3,96 & 1,00 & $0,96-1,05$ \\
\hline Parda & 782 & 2,62 & 2,80 & 2,85 & 2,94 & 3,44 & 3,29 & 3,33 & 3,45 & 3,14 & 2,93 & $1,03^{*}$ & $1,01-1,06$ \\
\hline Amarela & 21 & 2,47 & 2,65 & 2,69 & 2,77 & 3,25 & 3,11 & 3,15 & 3,25 & 2,96 & 2,77 & 1,07 & $0,91-1,26$ \\
\hline Indígena & 04 & 0,89 & 0,95 & 0,97 & 1,00 & 1,17 & 1,12 & 1,13 & 1,17 & 1,06 & 1,00 & 1,45 & $0,94-2,25$ \\
\hline \multicolumn{14}{|l|}{ Norte } \\
\hline Branca & 653 & 3,39 & 3,63 & 3,70 & 3,80 & 4,46 & 4,27 & 4,32 & 4,46 & 4,07 & 3,80 & 1,02 & 0,99-1,05 \\
\hline Preta & 232 & 3,61 & 3,86 & 3,93 & 4,05 & 4,74 & 4,54 & 4,59 & 4,75 & 4,32 & 4,05 & 1,01 & $0,97-1,06$ \\
\hline Parda & 2526 & 4,38 & 4,68 & 4,77 & 4,91 & 5,75 & 5,50 & 5,57 & 5,76 & 5,24 & 4,90 & $1,02^{*}$ & $1,01-1,03$ \\
\hline Amarela & 07 & 1,71 & 1,83 & 1,87 & 1,92 & 2,25 & 2,15 & 2,18 & 2,25 & 2,05 & 1,92 & 1,29 & $0,96-1,72$ \\
\hline Indígena & 35 & 3,77 & 4,04 & 4,11 & 4,23 & 4,96 & 4,74 & 4,80 & 4,97 & 4,52 & 4,23 & 0,87 & $0,77-0,99$ \\
\hline \multicolumn{14}{|l|}{ Nordeste } \\
\hline Branca & 907 & 1,16 & 1,24 & 1,27 & 1,30 & 1,53 & 1,46 & 1,48 & 1,53 & 1,39 & 1,30 & 1,01 & $0,99-1,03$ \\
\hline Preta & 403 & 1,34 & 1,43 & 1,46 & 1,50 & 1,76 & 1,68 & 1,70 & 1,76 & 1,60 & 1,50 & 0,98 & $0,95-1,02$ \\
\hline Parda & 3773 & 2,19 & 2,34 & 2,38 & 2,45 & 2,87 & 2,75 & 2,78 & 2,88 & 2,62 & 2,45 & $1,04^{*}$ & $1,03-1,05$ \\
\hline Amarela & 04 & 0,45 & 0,48 & 0,49 & 0,51 & 0,59 & 0,57 & 0,58 & 0,60 & 0,54 & 0,51 & $1,68^{* * * * * *}$ & $1,04-2,74$ \\
\hline Indígena & 09 & 0,92 & 0,99 & 1,01 & 1,04 & 1,21 & 1,16 & 1,18 & 1,22 & 1,11 & 1,04 & 0,88 & $0,70-1,11$ \\
\hline \multicolumn{14}{|l|}{ Centro-Oeste } \\
\hline Branca & 1562 & 4,51 & 4,82 & 4,91 & 5,05 & 5,92 & 5,66 & 5,73 & 5,93 & 5,40 & 5,05 & 0,99 & $0,97-1,00$ \\
\hline Preta & 242 & 3,68 & 3,94 & 4,01 & 4,13 & 4,84 & 4,63 & 4,69 & 4,85 & 4,41 & 4,13 & 0,98 & $0,94-1,03$ \\
\hline Parda & 2430 & 5,85 & 6,26 & 6,37 & 6,56 & 7,69 & 7,35 & 7,45 & 7,70 & 7,01 & 6,55 & $1,02^{*}$ & $1,01-1,04$ \\
\hline Amarela & 12 & 2,13 & 2,28 & 2,32 & 2,39 & 2,80 & 2,68 & 2,71 & 2,80 & 2,55 & 2,39 & 0,98 & $0,79-1,22$ \\
\hline Indígena & 08 & 2,26 & 2,42 & 2,47 & 2,54 & 2,97 & 2,85 & 2,88 & 2,98 & 2,71 & 2,54 & 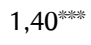 & $1,05-1,86$ \\
\hline \multicolumn{14}{|l|}{ Brasil } \\
\hline Branca & 17328 & 3,43 & 3,55 & 3,66 & 3,60 & 4,12 & 4,09 & 4,17 & 4,22 & 3,85 & 3,61 & 1,01 & $1,00-1,02$ \\
\hline Preta & 1966 & 2,48 & 2,15 & 2,46 & 2,61 & 2,78 & 2,82 & 2,73 & 2,77 & 2,18 & 2,05 & 0,99 & $0,98-1,01$ \\
\hline Parda & 13249 & 2,53 & 2,97 & 2,90 & 3,14 & 4,00 & 3,55 & 3,60 & 3,83 & 3,58 & 3,37 & $1,03^{*}$ & $1,02-1,04$ \\
\hline Amarela & 95 & 1,52 & 0,80 & 1,76 & 2,10 & 1,11 & 2,27 & 2,80 & 3,01 & 0,95 & 1,41 & 1,04 & $0,96-1,12$ \\
\hline Indígena & 58 & 1,56 & 2,08 & 1,72 & 0,43 & 3,43 & 1,30 & 1,39 & 1,94 & 3,02 & 1,36 & 1,02 & $0,94-1,12$ \\
\hline
\end{tabular}

* Leve tendência de crescimento nas taxas de mortalidade (até 5\%, em média, ao ano) com significância estatística; ** Moderado tendência de crescimento nas taxas de mortalidade (entre 6 e 10\%, em média, ao ano) com significância estatística; ****: Forte tendência de crescimento nas taxas de mortalidade (acima de 11\%, em média, ao ano) com significância estatística; (n) refere-se ao número de óbitos por acidentes de trabalho no período; TAM refere-se a taxa anual média no período; IC95\% refere-se aos intervalos de confiança de 95\%.

Fonte: SIM/DATASUS/Ministério da Saúde ${ }^{18}$. 
A maior taxa de mortalidade ocorreu entre os trabalhadores pardos da região Centro-Oeste no ano de 2014 (7,7/100 mil trabalhadores). Considerando o Brasil como um todo, a maior taxa foi registrada entre trabalhadores brancos no ano de 2014 (4,22/100 mil trabalhadores).

Embora, em números absolutos, as regiões Sul e Sudeste apresentem $61 \%$ dos óbitos, as taxas de mortalidade nessas regiões são mais baixas para os trabalhadores pretos e pardos em relação aos brancos. Dentre os trabalhadores brancos, as taxas de mortalidade mais altas foram de 7,24/100 mil no Sul, em 2013, e 5,93/100 mil na região Centro-Oeste, em 2014.

As maiores taxa de mortalidade por acidente de trabalho entre os amarelos foram nos anos de 2010 e 2013, com 2,80/100 mil na região Centro-Oeste e $3,25 / 100$ mil na região Sul. As maiores taxas de mortalidade entre os indígenas foram de 4,97/100 mil na região Norte, em 2013, e de 2,98/100 mil na região Centro-Oeste, em 2014.

Ao considerar as diferenças regionais na mortalidade por acidente de trabalho, observa-se que em 2015 a taxa de mortalidade foi $88 \%$ maior para os pardos em relação aos trabalhadores brancos no Nordeste, 29\% maior para pardos do que brancos da região Norte e 30\% maior para pardos do que para brancos na região Centro-Oeste (Tabela 2).

Nas regiões Sul e Sudeste, os brancos apresentaram maiores taxas de mortalidade por acidente de trabalho em relação a todas as outras raças, independente do ano estudado. Na região Sul, essa diferença é mais acentuada. Em 2015, por exemplo, a taxa de mortalidade entre os brancos foi 56\% maior em relação aos pretos e $110 \%$ maior em relação aos trabalhadores pardos. Na região Sudeste, a diferença entre as taxas é menor. Ainda assim, em 2015, a taxa de mortalidade para os trabalhadores brancos foi $22 \%$ maior em relação aos pretos e 11\% maior em relação aos pardos. Parece que no Sudeste há uma distribuição mais igualitária da mortalidade entre brancos, pretos e pardos (Tabela 2).

Considerando o Brasil como um todo, em 2015 observa-se que a taxa de mortalidade foi de 3,61/100 mil trabalhadores para brancos, 2,05/100 mil entre os pretos e de 3,37/100 mil entre os pardos. Embora a taxa de mortalidade seja semelhante entre os trabalhadores brancos e pardos, a tendência da mortalidade apresentou leve, porém significativo crescimento anual de 3\%, entre 2006 e 2015, para os pardos (Figura 2).

Com relação à escolaridade, considerando o Brasil como um todo, entre 2006 e 2015 houve tendência de crescimento da mortalidade entre os trabalhadores sem instrução e com ensino fundamental incompleto, com taxa de óbitos variando de 2,86 para 4,74 óbitos a cada 100 mil trabalhadores (aumento de $6 \%$ ao ano). Entre os trabalhadores com ensino fundamental completo e médio incompleto, a taxa de mortalidade foi de 2,64 para 5,75 a cada 100 mil trabalhadores (aumento de 9\% ao ano) (Figura 2).

As taxas de mortalidade mais altas ocorreram em 2013, entre trabalhadores sem instrução e com ensino fundamental incompleto $(9,87$ óbitos a cada 100 mil trabalhadores da região Centro-Oeste) e trabalhadores com ensino fundamental completo e ensino médio incompleto $(10,02$ óbitos a cada 100 mil trabalhadores da região Sul) (Tabela 3).

Entre os trabalhadores com os mais baixos níveis de escolaridade, observa-se um aumento médio anual nas taxas de mortalidade, variando de $5 \%$ a $10 \%$, nas regiões Centro-Oeste e Sul, respectivamente, enquanto as taxas para aqueles com mais alto nível de escolaridade vêm decaindo ao longo dos anos (Tabela 3).

Comparando as taxas de mortalidade por acidentes de trabalho de acordo com a escolaridade (Tabela 3), observa-se que em todos os anos do período e em todas as regiões do país trabalhadores com menor nível de escolaridade (sem instrução e com fundamental incompleto) tiveram maiores taxas da mortalidade. Em 2015, considerando o Brasil como um todo, a mortalidade entre os trabalhadores com o menor nível de escolaridade foi mais que 15 vezes maior $(4,74 / 0,31=15,3)$ do que entre aqueles com o mais alto nível de escolaridade. Esses dados revelam que trabalhadores com mais anos de estudos apresentam menor risco de morte. 


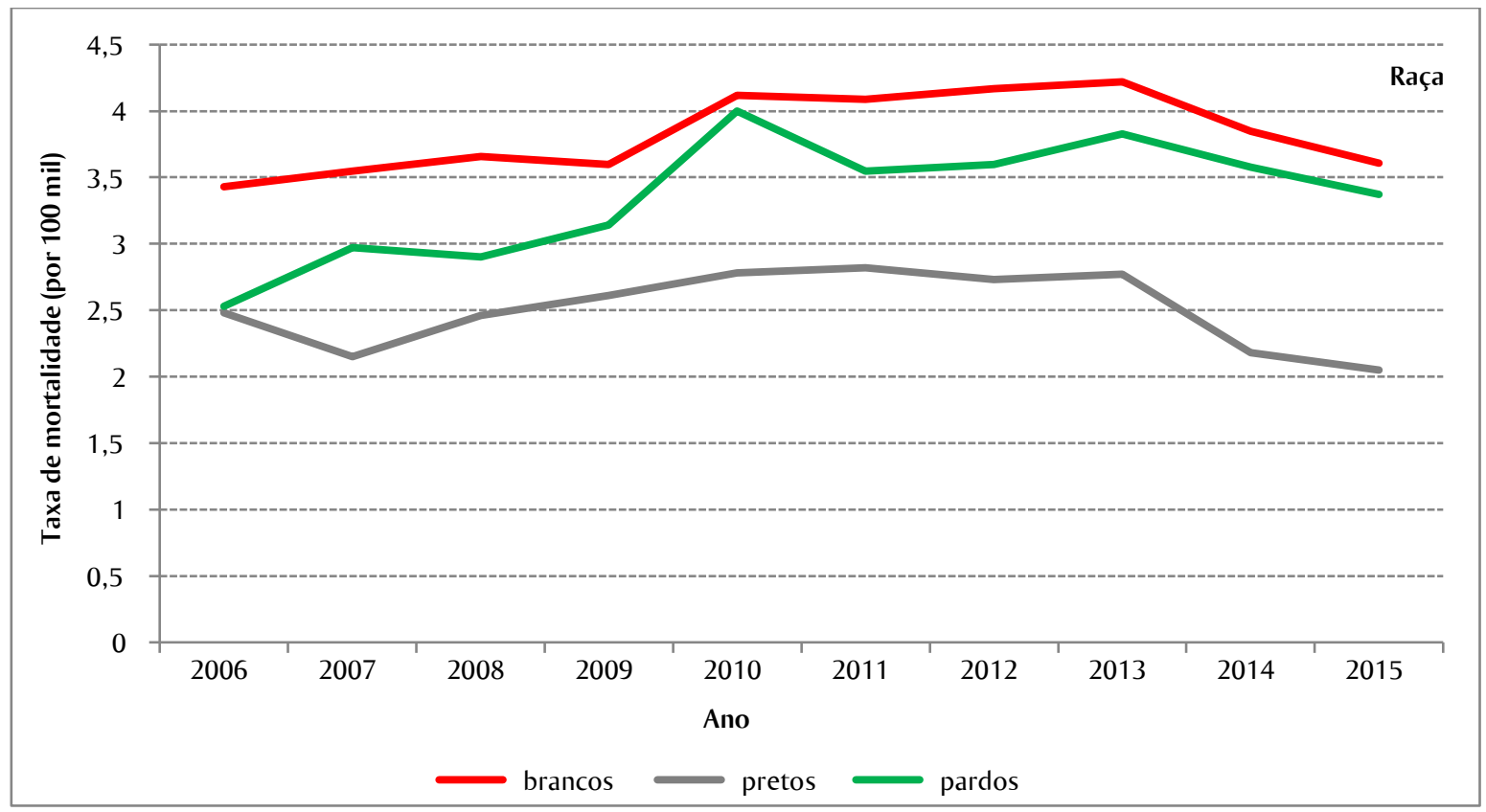

Obs: raças amarela e indígena não inseridas devido a alta variabilidade apresentada)

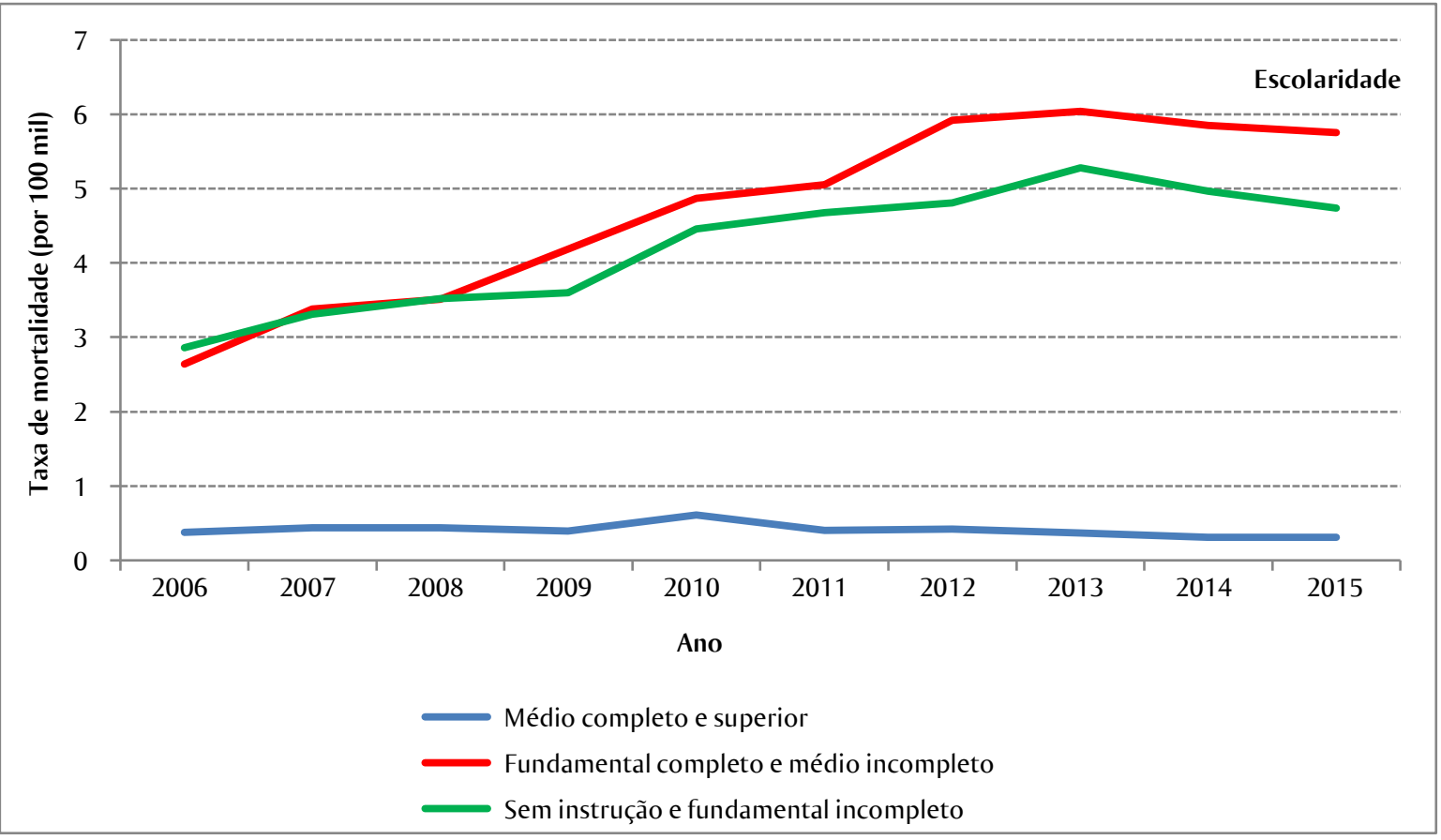

Figura 2 Taxa de mortalidade por acidente de trabalho (a cada 100 mil trabalhadores) de acordo com raça (Figura 2A) e escolaridade (Figura 2B), Brasil, 2006-2015 
Tabela 3 Número de óbitos e taxa de mortalidade por acidentes de trabalho estimada, por 100 mil trabalhadores, de acordo com ano, macrorregião do país e nível de escolaridade, Brasil, 2006-2015

\begin{tabular}{|c|c|c|c|c|c|c|c|c|c|c|c|c|c|}
\hline \multirow[b]{2}{*}{$\begin{array}{l}\text { Regiões do Brasil } \\
\text { Escolaridade }\end{array}$} & \multirow[b]{2}{*}{ (n) } & \multicolumn{10}{|c|}{ Taxa de mortalidade por ano } & \multicolumn{2}{|c|}{ 2006-2015 } \\
\hline & & 2006 & 2007 & 2008 & 2009 & 2010 & 2011 & 2012 & 2013 & 2014 & 2015 & TAM & IC95\% \\
\hline \multicolumn{14}{|l|}{ Sudeste } \\
\hline $\begin{array}{l}\text { Médio completo e } \\
\text { superior }\end{array}$ & 565 & 0,17 & 0,21 & 0,22 & 0,23 & 0,28 & 0,28 & 0,31 & 0,32 & 0,31 & 0,29 & 0,99 & $0,96-1,02$ \\
\hline $\begin{array}{l}\text { Fundamental } \\
\text { completo e médio } \\
\text { incompleto }\end{array}$ & 2.513 & 2,34 & 2,76 & 2,91 & 3,07 & 3,75 & 3,83 & 4,12 & 4,35 & 4,10 & 3,96 & $1,08^{m+}$ & $1,07-1,10$ \\
\hline $\begin{array}{l}\text { Sem instrução e fun- } \\
\text { damental incompleto }\end{array}$ & 4.138 & 2,24 & 2,65 & 2,80 & 2,95 & 3,60 & 3,67 & 3,95 & 4,18 & 3,94 & 3,80 & $1,07^{m+}$ & $1,06-1,09$ \\
\hline \multicolumn{14}{|l|}{ Sul } \\
\hline $\begin{array}{l}\text { Médio completo e } \\
\text { superior }\end{array}$ & 477 & 0,46 & 0,54 & 0,57 & 0,60 & 0,73 & 0,75 & 0,81 & 0,85 & 0,80 & 0,77 & 0,98 & $0,95-1,01$ \\
\hline $\begin{array}{l}\text { Fundamental } \\
\text { completo e médio } \\
\text { incompleto }\end{array}$ & 2.325 & 5,38 & 6,34 & 6,71 & 7,08 & 8,63 & 8,80 & 9,48 & 10,02 & 9,44 & 9,10 & $1,10^{m+n}$ & $1,08 \quad 1,12$ \\
\hline $\begin{array}{l}\text { Sem instrução e fun- } \\
\text { damental incompleto }\end{array}$ & 3.927 & 5,00 & 5,90 & 6,24 & 6,58 & 8,03 & 8,19 & 8,82 & 9,32 & 8,79 & 8,47 & $1,05^{*}$ & $1,04-1,07$ \\
\hline \multicolumn{14}{|l|}{ Norte } \\
\hline $\begin{array}{l}\text { Médio completo e } \\
\text { superior }\end{array}$ & 166 & 0,39 & 0,46 & 0,48 & 0,51 & 0,62 & 0,63 & 0,68 & 0,72 & 0,68 & 0,66 & 0,92 & $0,87-0,97$ \\
\hline $\begin{array}{l}\text { Fundamental } \\
\text { completo e médio } \\
\text { incompleto }\end{array}$ & 758 & 4,04 & 4,77 & 5,04 & 5,32 & 6,49 & 6,61 & 7,12 & 7,53 & 7,10 & 6,84 & $1,07^{\text {s* }}$ & $1,04-1,10$ \\
\hline $\begin{array}{l}\text { Sem instrução e fun- } \\
\text { damental incompleto }\end{array}$ & 1.975 & 4,03 & 4,75 & 5,02 & 5,30 & 6,47 & 6,59 & 7,10 & 7,50 & 7,07 & 6,82 & $1,06^{\text {"W" }}$ & $1,04-1,07$ \\
\hline \multicolumn{14}{|l|}{ Nordeste } \\
\hline $\begin{array}{l}\text { Médio completo e } \\
\text { superior }\end{array}$ & 232 & 0,17 & 0,21 & 0,22 & 0,23 & 0,28 & 0,28 & 0,31 & 0,32 & 0,31 & 0,29 & 0,94 & $0,90-0,98$ \\
\hline $\begin{array}{l}\text { Fundamental } \\
\text { completo e médio } \\
\text { incompleto }\end{array}$ & 1.047 & 1,89 & 2,23 & 2,36 & 2,49 & 3,03 & 3,09 & 3,33 & 3,52 & 3,32 & 3,20 & $1,06^{\text {th }}$ & $1,04-1,09$ \\
\hline $\begin{array}{l}\text { Sem instrução e fun- } \\
\text { damental incompleto }\end{array}$ & 2.904 & 1,55 & 1,83 & 1,94 & 2,04 & 2,49 & 2,54 & 2,73 & 2,89 & 2,73 & 2,63 & $1,07^{* *}$ & $1,05-1,08$ \\
\hline \multicolumn{14}{|l|}{ Centro-Oeste } \\
\hline $\begin{array}{l}\text { Médio completo e } \\
\text { superior }\end{array}$ & 271 & 0,52 & 0,62 & 0,65 & 0,69 & 0,84 & 0,85 & 0,92 & 0,97 & 0,92 & 0,88 & 0,94 & $0,91-0,98$ \\
\hline $\begin{array}{l}\text { Fundamental } \\
\text { completo e médio } \\
\text { incompleto }\end{array}$ & 1.019 & 5,13 & 6,06 & 6,41 & 6,76 & 8,25 & 8,41 & 9,05 & 9,57 & 9,02 & 8,69 & $1,08^{* *}$ & $1,06-1,11$ \\
\hline $\begin{array}{l}\text { Sem instrução e fun- } \\
\text { damental incompleto }\end{array}$ & 2.031 & 5,29 & 6,25 & 6,61 & 6,97 & 8,50 & 8,67 & 9,33 & 9,87 & 9,30 & 8,97 & $1,05^{* *}$ & $1,04-1,07$ \\
\hline \multicolumn{14}{|l|}{ Brasil } \\
\hline $\begin{array}{l}\text { Médio completo e } \\
\text { superior }\end{array}$ & 1.711 & 0,38 & 0,44 & 0,44 & 0,39 & 0,61 & 0,40 & 0,42 & 0,37 & 0,31 & 0,31 & 0,97 & $0,95-0,98$ \\
\hline $\begin{array}{l}\text { Fundamental } \\
\text { completo e médio } \\
\text { incompleto }\end{array}$ & 7.662 & 2,64 & 3,38 & 3,51 & 4,19 & 4,87 & 5,05 & 5,92 & 6,04 & 5,85 & 5,75 & $1,09^{m+}$ & $1,08-1,09$ \\
\hline $\begin{array}{l}\text { Sem instrução e fun- } \\
\text { damental incompleto }\end{array}$ & 14.944 & 2,86 & 3,31 & 3,52 & 3,60 & 4,46 & 4,68 & 4,81 & 5,28 & 4,97 & 4,74 & $1,06^{m+}$ & $1,06-1,07$ \\
\hline
\end{tabular}

* Leve tendência de crescimento nas taxas de mortalidade (até 5\%, em média, ao ano) com significância estatística; *** Moderada tendência de crescimento nas taxas de mortalidade (entre 6 e $10 \%$, em média, ao ano) com significância estatística; (n) refere-se ao número de óbitos por acidentes de trabalho no período; TAM refere-se a taxa anual média no período; IC95\% refere-se aos intervalos de confiança de $95 \%$.

Fonte: SIM/DATASUS/Ministério da Saúde ${ }^{18}$. 


\section{Discussão}

Esta pesquisa destacou os perfis de mortalidade por acidentes de trabalho no Brasil, entre 2006 e 2015, de acordo com sexo, faixa-etária, raça/cor, escolaridade e macrorregião do país. Os resultados permitem observar que embora, no geral, as taxas de mortalidade tenham se mantido relativamente estáveis, há disparidades em relação às características étnico-raciais, de faixa etária, gênero e entre as macrorregiões do país.

Com relação às características sociodemográficas (sexo, idade e escolaridade), os resultados deste estudo corroboram achados anteriores ${ }^{5,19-21}$, evidenciando que a maioria dos óbitos por acidente de trabalho no Brasil ocorrem entre trabalhadores homens, em idade produtiva (20 a 59 anos) e com baixo nível de escolaridade (sem instrução e fundamental incompleto). Assim, demonstra-se que as características sociodemográficas devem determinar diferentes exposições e vulnerabilidades que contribuem para a precariedade das condições de trabalho e as decorrentes iniquidades em saúde.

De acordo com a Pesquisa Nacional por Amostra de Domicílios (PNAD) de 2006, 60\% dos trabalhadores que estão no mercado de trabalho informal têm baixo nível de escolaridade (sem instrução e fundamental incompleto), ou seja, mais anos de estudo podem significar uma melhor inserção no mercado de trabalho. Essa população de trabalhadores que está no mercado informal é marcada pela precariedade das condições de trabalho e de vida, a negação dos princípios de cidadania, a perpétua reprodução da pobreza e das desigualdades sociais ${ }^{22}$. Vários estudos têm demonstrado que um menor nível de instrução tem relação com a ocupação de postos de trabalho mais precarizados, maior exposição a riscos e condições de segurança menos favoráveis, dentre outros elementos que prejudicam a saúde e o bem estar ${ }^{23,24}$.

Em relação ao sexo, a mortalidade por acidentes de trabalho é consideravelmente superior no masculino em relação ao feminino em todas as regiões do país. Nas faixas etárias entre 40 e 59 anos, por exemplo, a mortalidade entre os homens é 18 vezes maior em relação às mulheres. No Brasil, a taxa de mortalidade por 100 mil trabalhadores entre os homens variou de 2,95 a 7,77, enquanto entre as mulheres oscilou de 0,35 a 1,17 . Porém, quando considerada a região, podem ser observadas taxas mais altas, como é o caso de trabalhadores acima de 60 anos da região Sul, que têm taxa de mortalidade acima de 13/100 mil.

De acordo com dados da OIT, em todos os países onde a mortalidade por acidentes de trabalho é conhecida, as taxas são superiores entre os homens em relação às mulheres ${ }^{13}$. Isso se deve, em parte, ao fato de que os homens predominam em setores produtivos com maior risco (por exemplo, construção civil e transportes).

Dentre as taxas de mortalidade por acidente de trabalho apresentadas pela OIT, observa-se que as dos países com maior igualdade de gênero são disparadamente mais baixas em relação aos países com maior desigualdade. Em 2011, a Noruega apresentou uma taxa de 3,2 óbitos entre os homens (a cada 100 mil trabalhadores) e de 1,0 para as mulheres (por 100 mil trabalhadores); a Suécia apresentou taxa de mortalidade de 2,1 óbitos a cada $100 \mathrm{mil}$ trabalhadores homens e 0,3 óbitos a cada 100 mil mulheres, e a Finlândia apresentou taxa de 2,6 entre os homens e 0,0 (zero) entre as mulheres (por 100 mil trabalhadores) ${ }^{13}$.

Por outro lado, no mesmo ano, países com maior desigualdade de gênero apresentaram taxas de mortalidade por acidente de trabalho muito superiores, como é o caso do Brasil, onde foi de 11,9 a cada 100 mil homens e de 1,2 a cada 100 mil mulheres. O México apresentou taxa de 15,3 óbitos a cada 100 mil homens e de 2,3 a cada 100 mil mulheres; e a Argentina teve taxa de 11,4 óbitos a cada $100 \mathrm{mil}$ homens e de 0,6 a cada 100 mil mulheres ${ }^{13}$.

O relatório do Fórum Econômico Mundial de 2018 destaca a forte correlação entre a desigualdade de gênero de um país e seu desempenho econômico, sugerindo que as diferenças de gênero nas indústrias se refletem nos desequilíbrios ocupacionais. Nesse sentido, destaca a necessidade de políticas públicas de igualdade de gênero para os países que desejam permanecer competitivos ${ }^{25}$. Importante salientar que os quatro países com maior desigualdade de gênero, de acordo com o relatório do Fórum Econômico Mundial, não têm seus dados divulgados na lista da OIT.

Países com cultura que reforçam a masculinidade, onde os valores estão centrados no dinheiro, sucesso material e no progresso sobre relacionamentos, apresentam maiores taxas de acidentalidade. A masculinidade extrema, comumente chamada de cultura do "ser macho", evoca necessidade de desafio, progresso e distinção, o que pode resultar na perda de relações interpessoais e de comunicação adequada, elementos que interferem negativamente para uma boa cultura de segurança $\mathrm{a}^{26}$.

De acordo com Park ${ }^{27}$, países com culturas voltadas à masculinidade provavelmente terão mais desastres provocados pelo homem do que aqueles com culturas mais femininas, que estimulam o nutrir e o cuidar. As sociedades com maior igualdade nesse aspecto dependem menos do sexo biológico para determinar a alocação de papéis entre os gêneros e procuram minimizar as diferenças entre as funções dos homens e das mulheres nas sociedades. 
Em geral, países com "cultura machista” promovem e recompensam os valores tidos como "masculinos", como assertividade, agressividade e comportamentos de risco. Nesse sentido, a cultura do "ser macho" implica assumir riscos, e isso pode ser estimulado ou recompensado por alguns setores produtivos, gerando uma cultura de insegurança na organização.

Esta pesquisa destaca o crescimento da mortalidade entre as mulheres (de, em média, 10\% ao ano para trabalhadoras de 20 a 30 anos da região Sudeste, e 21\% entre trabalhadoras acima de 60 anos de idade da região Centro-Oeste). Possivelmente o crescimento da mortalidade por acidentes de trabalho entre as mulheres sinaliza a crescente inserção delas no mercado de trabalho, inclusive em postos tipicamente ocupados por homens.

Embora alguns estudos tenham demonstrado que a taxa de mortalidade por acidentes de trabalho no Brasil tem diminuído ao longo dos anos ${ }^{4,12}$, esta pesquisa identificou que a tendência da mortalidade tem se mantido estável apenas para algumas categorias de análise e em determinadas regiões. No período compreendido entre 2006 e 2015, houve leve aumento da mortalidade por acidente de trabalho entre homens das faixas etárias extremas. Nota-se aumento de 5\%, em média, na mortalidade de trabalhadores com entre 15 e 19 anos; aumento de 3\%, em média, para aqueles acima de 60 anos de idade; e aumento de $5 \%$ na taxa das mulheres entre 20 e 29 anos. Em relação à raça, nota-se aumento de 3\% na mortalidade entre trabalhadores pardos. No que se refere à escolaridade, observou-se moderado crescimento na mortalidade, com aumento de $9 \%$ entre trabalhadores com ensino fundamental completo e médio incompleto, e de $6 \%$ para aqueles sem instrução e com ensino fundamental incompleto.

Uma revisão acerca da mortalidade por acidentes de trabalho no Brasil encontrou elevadas taxas de mortalidade ${ }^{12}$. Entretanto, foi observada tendência de queda ao longo dos anos, no período entre 1990 e 2003. De 26,2/100 mil em 1990, a taxa de mortalidade reduziu para 18,9/100 mil em 1995. Entre 1996 e 1997, houve ligeiro aumento para 21,5/100 mil, ficando relativamente estável nos dois anos seguintes, quando voltou a cair, chegando a 11,4/100 mil em 2003. Portanto, no período estudado, houve uma redução de $56,5 \%$ na mortalidade ${ }^{12}$.

O estudo conduzido por Almeida, Morrone e Ribeiro ${ }^{4}$ apontou tendência significativa de decréscimo na taxa de mortalidade por acidentes de trabalho no período entre 1998 e 2008. A maior taxa de mortalidade ajustada foi de 22,5 óbitos por 100 mil trabalhadores segurados pelo INSS, no ano 1999, enquanto a menor taxa foi de 9,9 por $100 \mathrm{mil}$, em 2008. Os autores destacam que as melhorias das condições de trabalho e maior crescimento do setor de serviços do que do setor industrial podem ter contribuído positivamente com a redução da mortalidade por acidentes de trabalho no período observado, enquanto a subnotificação dos acidentes de trabalho e a terceirização dos serviços podem ter contribuído negativamente.

Em nosso estudo, a comparação das taxas de mortalidade por acidente de trabalho de acordo com raça/cor permite observar que, nas regiões Norte, Nordeste e Centro-Oeste, os pardos têm maior mortalidade do que os brancos, sendo que as maiores taxas entre pardos e pretos foram registradas nas regiões Centro-Oeste e Norte.

Vários estudos evidenciam a associação entre características étnico-raciais e taxas de acidentalidade e mortalidade por acidentes de trabalho, sugerindo que os negros e imigrantes são mais vulneráveis ${ }^{14,16,28,29}$. A pesquisa de Seabury, Terp e Boden $^{14}$ com dados de trabalhadores nos Estados Unidos da América evidenciou que determinados grupos étnicos/raciais (trabalhadores negros não-hispânicos e trabalhadores estrangeiros) trabalhavam em situações de maior risco de lesão, levando a um aumento significativo na prevalência de incapacidades relacionadas ao trabalho.

Um estudo realizado com adolescentes americanos, de 15 a 17 anos, concluiu que os grupos minoritários (afro-americanos e hispânicos) eram significativamente mais propensos a sofrer algum acidente de trabalho grave em comparação com adolescentes brancos em postos de trabalho semelhantes. Algumas características do trabalho foram responsáveis por condições mais perigosas (por exemplo, trabalhar mais horas por semana e durante a noite), levando a um maior número de lesões entre os grupos minoritários ${ }^{16}$.

Trabalhadores hispânicos e negros na Califórnia estão expostos a maiores riscos de acidentes de trabalho em relação a trabalhadores brancos e não hispânicos, mesmo depois de controlar a análise por escolaridade e experiência profissional. Suspeita-se que essas diferenças étnicas possam estar associadas a diferentes características do trabalho (como salários mais baixos, menos autonomia e controle do ritmo, menos tempo de treinamento) ${ }^{28}$.

Shannon et al. ${ }^{29}$ evidenciaram relação entre raça/ etnia com experiências de discriminação racial no trabalho nos Estados Unidos da América. O estudo evidenciou que as probabilidades de discriminação racial no trabalho foram entre 3 e 8 vezes maiores entre as minorias (negros e hispânicos) quando comparados aos brancos. Os trabalhadores que sofreram discriminação no trabalho foram duas vezes mais propensos a relatar doença/lesão/violência, com significância estatística, do que do que aqueles sem discriminação. 
Com relação a diferenças regionais nas taxas de mortalidade por acidente de trabalho no Brasil, o Sudeste se destacou como a região com melhor distribuição da mortalidade entre brancos, pretos e pardos. A região Sul apresentou as maiores taxas de mortalidade de todo o país. Este resultado pode estar relacionado com a eficácia da notificação por acidente de trabalho nos estados dessa região.

Embora sem significância estatística, a mortalidade anual média aumentou entre os trabalhadores amarelos e indígenas das regiões Sudeste, Sul e Norte, enquanto na região Centro-Oeste a mortalidade entre os indígenas aumentou 40\%, com significância estatística. O aumento nas taxas de mortalidade dos amarelos e indígenas indica possível melhoria na notificação dos acidentes de trabalho relacionados a esses grupos de trabalhadores, desvelando, por um lado, uma melhoria no processo notificatório e, por outro, maior inserção no mercado de trabalho em postos de maior risco para a saúde e segurança.

Os achados desta pesquisa expressam possíveis diferenças nas oportunidades e condições de trabalho entre as pessoas, o que faz com que populações mais vulneráveis (pretos, pardos e indígenas) sejam expostas a um maior risco de morte por acidentes de trabalho, especialmente nas regiões Norte, Nordeste e Centro-Oeste.

Importante salientar que apesar de os achados deste estudo indicarem disparidades étnico-raciais nas taxas de mortalidade nas diferentes regióes do Brasil, é necessário lembrar que o fenômeno da subnotificação pode ser mais acentuado para trabalhadores negros. Drumond e Silva ${ }^{30}$ observaram sub-registros no SIM e no Sistema de Informação de Agravos de Notificação (Sinan) e identificaram que a maioria dos casos de subnotificação de óbitos ocorreram com homens $(94,3 \%)$, negros $(47,5 \%)$ e com menos de oito anos de escolaridade $(36,9 \%)$.

O presente estudo possui algumas limitações. A primeira diz respeito ao fato de os achados revelarem somente uma parte da realidade, considerando o problema crônico da subnotificação por acidentes de trabalho no Brasil decorrente tanto da produção, quanto da qualidade dos dados ${ }^{8,12,30-34}$. De acordo com Hennington, Cordeiro e Moreira Filho ${ }^{8}$, as informações sobre mortalidade por acidentes de trabalho advindas do Ministério do Trabalho e Emprego no Estado de São Paulo entre junho de 1999 e maio de 2000 estão subestimadas em 83,4\%. Corroborando esses achados, Cordeiro et al. ${ }^{31}$ estimaram em 79,5\% a subnotificação de acidentes de trabalho não fatais.

Outra limitação deste estudo diz respeito à qualidade das informações sobre os óbitos obtidas pelo SIM, pois podem subestimar os números reais sobre os óbitos relacionados ao trabalho. Considerando que o preenchimento da DO é realizado pelo médico, cabe a ele preencher adequadamente o campo relacionado à raça/cor/etnia. Nesse sentido, é sabido que há fragilidade no preenchimento deste campo, uma vez que nem todos os profissionais de saúde, desde os trabalhadores que atuam na recepção até os médicos, não são tradicionalmente treinados para realizar a heteroidentificação, que deve ser feita preferencialmente com ajuda de um membro da família ou responsável. Além disso, sabe-se que há várias dificuldades para coletar informações sobre cor ou raça/etnia, relacionadas ao processo histórico de escravidão da população negra que, por vezes, levam a reações desfavoráveis dos usuários (como constrangimentos, irritação, arrogância, agressividade, desconfiança ou dúvida) e acabam contribuindo para que os profissionais que atuam na saúde não preencham este campo nos prontuários. São, enfim, questões que precisam ser superadas para que se possa melhorar o preenchimento deste dado nos prontuários e, consequentemente, nas declarações de óbito. Como essas dificuldades ainda permeiam os sistemas de saúde, suspeita-se que pessoas de cor preta ou parda não tenham sido identificadas como tal nas DO usadas neste estudo, portanto, as taxas aqui apresentadas podem estarem subestimadas.

Os resultados deste estudo são bastante impactantes e referem-se a trabalhadores formais e informais, mas na prática é possível que reflitam mais a realidade dos trabalhadores formais. é possível que os acidentes de trabalho relacionados aos trabalhadores informais ainda sejam subnotificados, revelando uma realidade ainda mais dramática no Brasil.

Uma das limitações deste estudo é não apresentar efeito sinérgico das características raça/cor, escolaridade, sexo e faixa etária. Ademais, apesar de ajuste por principais fatores de risco considerados na análise populacional de saúde ocupacional, não foi possível excluir possível influência dos demais mediadores de efeito e dos fatores de confundimento. Entretanto, há que se ressaltar que as informações apresentadas neste artigo apresentam relevância ao estratificar a mortalidade por acidente de trabalho de acordo com as macrorregiões do país. Nesse sentido, têm potencial para contribuir com o planejamento de ações em saúde do trabalhador no âmbito do SUS, especialmente aquelas relacionadas à Vigilância em Saúde; além de subsidiar informações para ações do Ministério Público do Trabalho em todo o território nacional.

Este artigo apresentou as taxas de mortalidade por acidentes de trabalho no Brasil evidenciando que existem grupos populacionais (homens, pretos, pardos, indígenas, pessoas com baixa escolaridade) e regiões do país (Norte, Nordeste e Centro-Oeste) mais vulneráveis. Espera-se que estes resultados 
possam subsidiar ações de melhoria das condições de segurança e saúde destes grupos de trabalhadores. Dentre os maiores desafios, destacam-se as ações de vigilância em saúde do trabalhador e o desenvolvimento de políticas públicas para o enfrentamento dos determinantes sociais relacionados à mortalidade por acidente de trabalho, com foco na redução das iniquidades.

\section{Contribuições de autoria}

Menegon LS, Menegon FA e Kupek E contribuíram substancialmente na concepção do estudo, no levantamento, análise e interpretação dos dados, na elaboração, revisões críticas e na aprovação da versão final publicada e assumem responsabilidade pública integral pelo estudo realizado e o conteúdo aqui publicado.

\section{Referências}

1. Organización Internacional del Trabajo. La prevención de las enfermedades profesionales. Geneva: OIT; 2013.

2. Takala J, Hämäläinen P, Saarela KL, Yun LY, Manickam K, Jin TW, et al. Global estimates of the burden of injury and illness at work in 2012. J Occup Environ Hyg [Internet]. 2014 [citado em 26 fev 2019];11(5):32637. Disponível em: https:// www.ncbi.nlm.nih.gov/pubmed/24219404

3. Brasil. Ministério da Fazenda. Secretaria de Previdência. Anuário estatístico da previdência social (vol. 24). Brasília, DF: Ministério da Fazenda; 2017.

4. Almeida FSS, Morrone LC, Ribeiro KB. Tendências na incidência e mortalidade por acidentes de trabalho no Brasil, 1998 a 2008. Cad Saude Publica [Internet]. 2014 [citado em 21 fev 2019];30(9):195764. Disponível em: https:/www.scielo.br/j/csp/a/kxTQ93 mdCXpStcGx5tSMSDQ/?lang=pt

5. Malta DC, Stopa SR, Silva MMA, Szwarcwald CL, Franco MS, Santos FV, et al. Acidentes de trabalho autorreferidos pela população adulta brasileira, segundo dados da Pesquisa Nacional de Saúde, 2013. Cien Saude Colet [Internet]. 2017 [citado em $21 \mathrm{fev}$ 2019];22(1):16978. Disponível em: https://www. scielo.br/j/csc/a/YP5DzH76QHBRx6QKnFdbgDs/ ?lang $=\mathrm{pt}$

6. Hämäläinen P. The effect of globalization on occupational accidents. Saf Sci [Internet]. 2009 [citado em 22 mar 2019];47(6):73342. Disponível em: http://www.sciencedirect.com/science/article/ pii/S0925753508000301

7. Hämäläinen P, Takala J, Saarela KL. Global estimates of occupational accidents. Saf Sci [Internet]. 2006 [citado em $28 \mathrm{fev}$ 2019];44(2):13756. Disponível em: http:// www.sciencedirect.com/science/article/pii/ S0925753505000871

8. Hennington ÉA, Cordeiro R, Moreira Filho DC. Trabalho, violência e morte em Campinas, São Paulo, Brasil. Cad Saude Publica [Internet]. 2004 [citado em 21 fev 2019];20(2):6107. Disponível em: https://www.scielo.br/j/csp/a/ FFqZ3dTx8ZHf5X9T693fNCD/?lang=pt
9. Santana VS, Araújo-Filho JB, Albuquerque-Oliveira PR, Barbosa-Branco A. Acidentes de trabalho: custos previdenciários e dias de trabalho perdidos. Rev Saude Publica [Internet]. 2006 [citado em 21 fev 2019];40(6):100412. Disponível em: https:// www.scielo.br/j/rsp/a/FhcxwZVjRCmWDySm4gxd $\mathrm{PRh} /$ lang $=\mathrm{pt}$

10. Cavalcante CAA, Santos RS, Cavalcante EFO, Martins RL, Silveira EA, Silva ET. Perfil dos agravos relacionados ao trabalho notificados no Rio Grande do Norte, 2007 a 2009. Epidemiol Serv Saude [Internet]. 2014 [citado em 26 fev 2019];23(4):74152. Disponível em: http://scielo.iec. gov.br/scielo.php?script $=$ sci_arttext $\&$ pid $=$ S167949742014000400016\&lng $=\overline{p t} \& n r m=i s o \& t \operatorname{lng}=p t$

11. Galdino A, Santana VS, Ferrite S. Os Centros de Referência em Saúde do Trabalhador e a notificação de acidentes de trabalho no Brasil. Cad Saude Publica [Internet]. 2012 [citado em 21 fev 2019];28(1):14559. Disponível em: https://www.scielo.br/j/csp/a/ X5tn8RT9WLQNBqxttVYs7kn/?lang=pt

12. Santana V, Nobre L, Waldvogel BC. Acidentes de trabalho no Brasil entre 1994 e 2004: uma revisão. Cien Saude Colet [Internet]. 2005 [citado em 28 fev 2019];10(4):84155. Disponível em: https:// www.scielo.br/j/csc/a/zBJybkgLpqdgnknMZnTQk $\mathrm{Mm} /$ lang $=\mathrm{pt}$

13. International Labour Organization. Ilostat: the world's leading source of labour statistics [Internet].Geneva: ILO; 2019 [citado em 28 mar 2019]. Disponível em: https://www.ilo.org/ shinyapps/bulkexplorer37/?lang $=\mathrm{en}$

14. Seabury SA, Terp S, Boden LI. Racial and ethnic differences in the frequency of workplace injuries and the prevalence of work-related disability. Heal Aff. 2017;36(2):26673.

15. Simpson CL, Severson RK. Risk of injury in African American hospital workers. J Occup Environ Med. 2000;42(10):103540.

16. Zierold KM, Anderson HA. Racial and ethnic disparities in work-related injuries among teenagers. J Adolesc Heal [Internet]. 2006 [citado em 1 mar 2019];39(3):4226. Disponível em: 
http://www.sciencedirect.com/science/article/pii/ S1054139X06000243

17. Melchior C, Zanini RR. Mortality per work accident: a literature mapping. Saf Sci [Internet]. 2019 [citado em 10 fev 2019];114:728. Disponível em: http://www.sciencedirect.com/science/article/ pii/S0925753518312177

18. Brasil. Ministério da Saúde. Mortalidade - desde 1996 pela CID-10 [Internet]. Brasília, DF: Ministério da Saúde; c2021 [citado em 6 out 2021]. Disponível em: https://datasus.saude.gov.br/mortalidadedesde-1996-pela-cid-10

19. Miranda FMD, Scussiato LA, Kirchhof ALC, Cruz EDA, Sarquis LMM. Caracterização das vítimas e dos acidentes de trabalho fatais. Rev Gaucha Enferm [Internet]. 2012 [citado em 21 fev 2019];33(2):4551. Disponível em: https://www.scielo.br/j/rgenf/a/ NbLKb8p69jVXqrVTjZyCCDy/?lang=pt

20. Lacerda KM, Fernandes RCP, Nobre LCC. Acidentes de trabalho fatais em Salvador, BA: descrevendo o evento subnotificado e sua relação com a violência urbana. Rev Bras Saude Ocup [Internet]. 2014 [citado em 21 fev 2019];39(129):6374. Disponível em: https://www.scielo.br/j/rbso/a/ D9FrJ8vqSF5LrhNDHdGT8Md/?lang=pt

21. Iwamoto HH, Camargo FC, Tavares LC, Miranzi SSC. Acidentes de trabalho fatais e a qualidade das informações de seus registros em Uberaba, em Minas Gerais e no Brasil, 1997 a 2006. Rev Bras Saude Ocup [Internet]. 2011 [citado em $21 \mathrm{fev}$ 2019];36(124):20815. Disponível em: https://www. scielo.br/j/rbso/a/bmRYvMxgk5DT78MbBbqkTtt/ ?lang $=\mathrm{pt}$

22. Costa MS. Trabalho informal: um problema estrutural básico no entendimento das desigualdades na sociedade brasileira. Cad CRH. 2010;23(58):17190.

23. Barlas B, Izci FB. Individual and workplace factors related to fatal occupational accidents among shipyard workers in Turkey. Saf Sci [Internet]. 2018 [citado em 21 fev 2019];101:1739. Disponível em: http://www.sciencedirect.com/science/article/ pii/S0925753517315850

24. Oliveira LG, Souza LMA, Barroso LP, Gouvêa MJC, Almeida CVD, Muñoz DR, et al. Occupational conditions and the risk of the use of amphetamines by truck drivers. Rev Saude Publica [Internet]. 2015 [citado em 21 maio 2019];49:19. Disponível em: https://www.scielo.br/j/rsp/a/VC8Mf7QPv5T6c R495p6txwm/?lang=en

25. World Economic Forum. The Global Gender Gap Index 2018 [Internet]. Geneva: World Economic Forum; 2018 [citado em 28 mar 2019]. Disponível em: http://reports.weforum.org/global-gender-gapreport-2018/the-global-gender-gap-index-2018/
26. Mearns K, Yule S. The role of national culture in determining safety performance: challenges for the global oil and gas industry. Saf Sci [Internet]. 2009 [citado em 27 mar 2019];47(6):77785. Disponível em: http://www.sciencedirect.com/science/article/ pii/S0925753508000295

27. Park H. Man-made disasters: a cross-national analysis. Int Bus Rev [Internet]. 2011 [citado em 27 mar 2019];20(4):46676. Disponível em: http://www.sciencedirect.com/science/article/pii/ S0969593110000971

28. Robinson JC. Exposure to occupational hazards among Hispanics, blacks and non-Hispanic whites in California. Am J Public Health [Internet]. 1989 [citado em 1 mar 2019];79(5):62930. Disponível em: https://www.ncbi.nlm.nih.gov/ pubmed/2631689

29. Shannon CA, Rospenda KM, Richman JA, Minich LM. Race, racial discrimination, and the risk of work-related illness, injury, or assault: findings from a national study. J Occup Environ Med [Internet]. 2009 [citado em 29 mar 2019];51(4):4418. Disponível em: https://www.ncbi. nlm.nih.gov/pubmed/19339900

30. Drumond EF, Silva JM. Avaliação de estratégia para identificação e mensuração dos acidentes de trabalho fatais. Cien Saude Colet [Internet]. 2013 [citado em 21 fev 2019];18(5):13615. Disponível em: https://www.scielo.br/j/csc/a/ 3qhxdxkpR48msjmKT5QWkbp/?lang=pt

31. Cordeiro R, Sakate M, Clemente APG, Diniz CS, Donalisio MR. Subnotificação de acidentes do trabalho não fatais em Botucatu, SP, 2002. Rev Saude Publica [Internet]. 2005 [citado em 25 mar 2019];39(2):25460. Disponível em: https://www. scielo.br/j/rsp/a/y9b7Djvh4YKSL65FYr3HtWG/ ?lang $=\mathrm{pt}$

32. Galdino A, Santana VS, Ferrite S, Galdino A, Santana VS, Ferrite S. Quality of the record of data on fatal workplace injuries in Brazil. Rev Saude Publica [Internet]. 2017 [citado em 21 fev 2019];51:120. Disponível em: https://www.revistas. usp.br/rsp/article/view/141557

33. Lacerda KM, Fernandes RCP, Nobre LCC, Pena PGL. A (in)visibilidade do acidente de trabalho fatal entre as causas externas: estudo qualitativo. Rev Bras Saude Ocup [Internet]. 2014 [citado em $21 \mathrm{fev}$ 2019];39(130):12735. Disponível em: https://www. scielo.br/j/rbso/a/8yQVfTfHMFCdQ45dT8bhS7R/ ?lang $=\mathrm{pt}$

34. Cordeiro R, Luz VG, Hennington ÉA, Martins ACA, Tófoli LF. A violência urbana é a maior causa de acidente de trabalho fatal no Brasil. Rev Saude Publica. 2017;51:123. 